\title{
Probabilistic Methodology For Life Prediction of Aircraft Turbine Rotors
}

\author{
M. P. Enright ${ }^{1}$, L. Huyse ${ }^{2}$, R. C. McClung ${ }^{3}$, and H.R. Millwater ${ }^{4}$
}

\section{Abstract}

The presence of rare metallurgical or manufacturing anomalies in aircraft turbine rotors/disks may contribute to uncontained engine failures. A probabilistic methodology has been developed to quantify the risk of fracture and the influence of periodic inspection on overall risk, supplementing the current safe life approach. This paper summarizes the methodology and computational implementation, including a brief description of a new method for defining surface damage-related crack growth using 3D finite element results. The results can be applied to risk assessment of aerospace structures where uncertainties associated with fatigue crack growth must be quantitatively addressed.

\section{Introduction}

Nearly a decade ago, the Federal Aviation Administration (FAA) and the Rotor Integrity Subcommittee (RISC) of the Aerospace Industries Association (AIA) proposed a probabilistic damage tolerance approach to account for the presence of metallurgical (inherent) and manufacturing (surface damage) anomalies that can occur during the manufacturing process (Leverant et al. 1997, 2003). This recommendation, based on the results of a National Transportation Safety Board report (NTSB 1990) linking metallurgical anomalies to uncontained engine events, led to the development of an advisory circular (FAA 2001) and the Turbine Rotor Material Design (TRMD) research program (Leverant et al. 2000) and associated DARWIN $^{\circledR}$ (Design Assessment of Reliability with INspection) computer software (Southwest Research Institute 2003).

DARWIN is a simulation-based program used to predict the probability of fracture of rotors and disks in commercial aircraft gas turbine engines. Six primary random

${ }^{1}$ Member, ASCE; Southwest Research Institute, 6220 Culebra Road, San Antonio, TX 78238-5166; PH (210) 522-2033; FAX (210) 522-6965; email:

michael.enright@swri.org

${ }^{2}$ Member, ASCE; Southwest Research Institute, 6220 Culebra Road, San Antonio, TX 78238-5166; PH (210) 522-2931; FAX (210) 522-6965; email:

luc.huyse@swri.org

${ }^{3}$ Southwest Research Institute, 6220 Culebra Road, San Antonio, TX 78238-5166; PH (210) 522-2422; FAX (210) 522-6965; email: craig.mcclung@swri.org ${ }^{4}$ University of Texas at San Antonio, 6900 North Loop 1604 West, San Antonio, TX 78249; PH (210) 458-4481; FAX (210) 458-5516; email: hmillwater@utsa.edu 
variables are used to model crack growth behavior and associated risk:

- defect size and occurrence rate

- stress scatter

- life scatter (i.e., crack growth rate variability)

- inspection quality (probability of detecting a defect)

- inspection time

Deterministic crack growth computations are performed using Flight_Life, an internal fracture mechanics module that includes a number of advanced capabilities such as crack transitioning and stress intensity factor solutions for multidimensional stress fields. A simulation-based framework is used for probabilistic life prediction including a capability to quantify the influence of periodic inspections on the risk of fracture.

\section{General Probabilistic Approach}

A probabilistic methodology has been developed to predict the risk of fracture associated with both inherent and surface damage-based defects (Figures 1a and 1b, respectively). A comparison of the primary differences in the current methodology for these two defect types is given in Table 1. It is assumed that inherent defects can occur anywhere within a component, so the probability of occurrence of a defect is directly proportional to the volume of the component. In contrast, surface damagerelated defects are assumed to occur only at specific features, so the probability of occurrence of a defect is based on the number of features and the surface area associated with each feature. A defect distribution has been developed for hard alpha

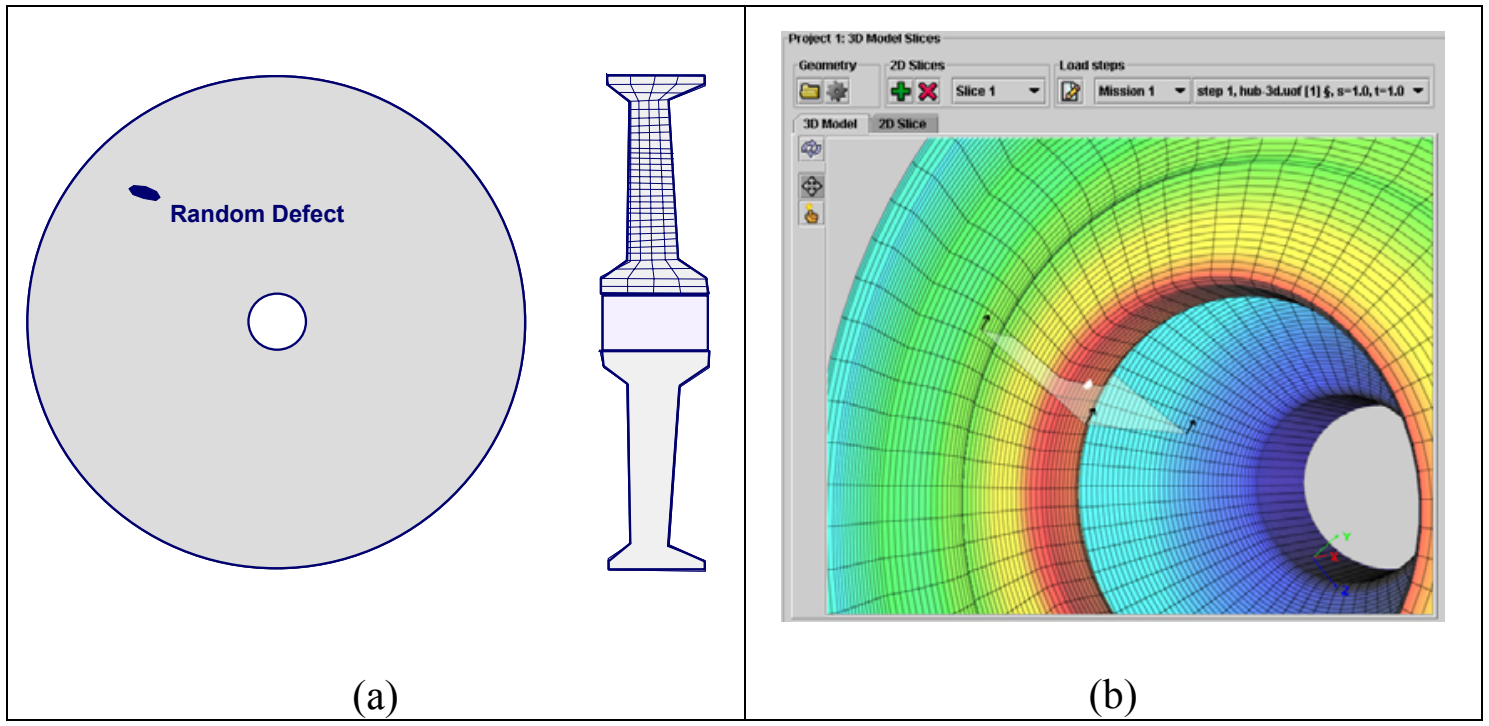

Figure 1. A probabilistic methodology has been developed to predict the risk of fracture associated with (a) inherent material defects, and (b) surface damage-based defects. 
Table 1. Summary of the primary differences in the damage tolerance approach for inherent and surface-damage-based defects in DARWIN

Defect Type
Risk basis

Component Volume

Surface Feature Area
Stress Gradient \&

Temperature Data

2D Finite Element Model

Surface Damage

inherent defects (Aerospace Industries Association 1997). Another distribution is under development for surface damage at machined bolt holes.

\section{Strategy for Inherent Material Defects}

For analysis of components containing inherent defects, a zone-based approach is used in which a component is subdivided into volumes of approximately equal risk. Component risk is approximately equal to the sum of the risks of the individual zones (Millwater 2000). Currently, this is accomplished using the results from a 2-D axisymmetric finite element model, in which finite elements are assigned to specific zones (Figure 2). Each zone can have a number of unique characteristics associated with it (e.g., stress gradient, crack growth rate model and associated variability, stress intensity factor solution type, number and quality of inspections, among others). The zone represents a volume of material in which an inherent defect may be present. A capability is provided for iteratively improving zone discretization based on the contribution of each zone to overall risk (Millwater et al. 2002). Additional details

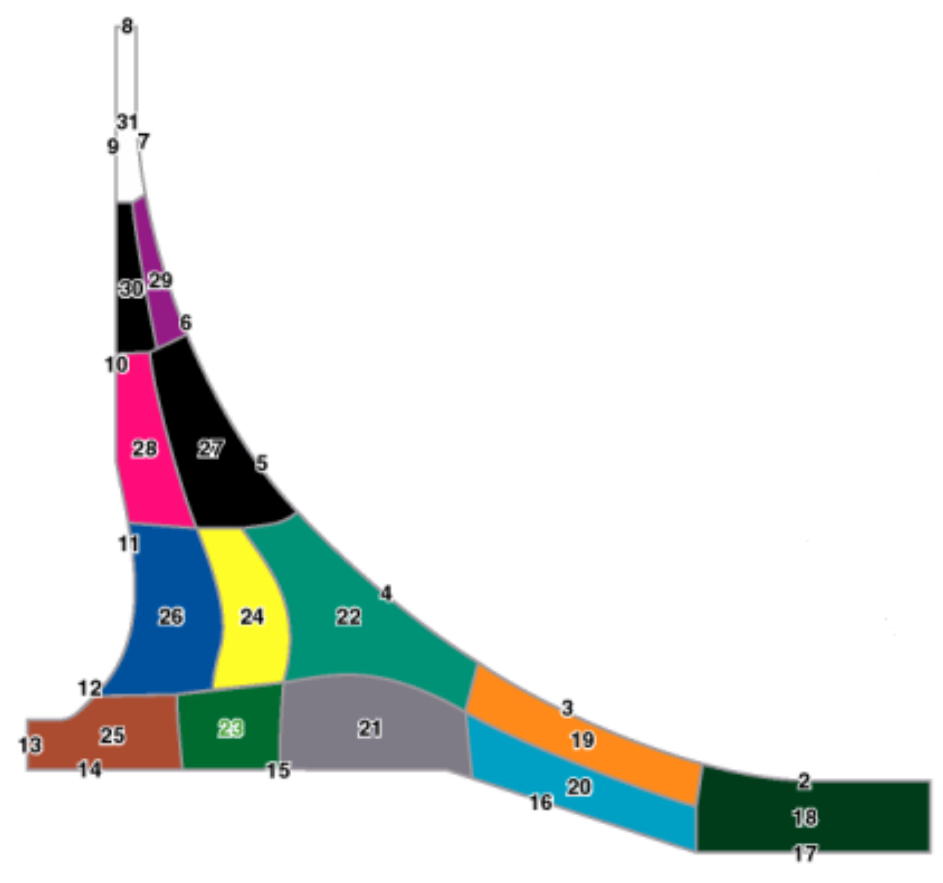

Figure 2. A zone-based approach is used for inherent (material) defects in which the component is subdivided into regions of approximately equal risk. 
regarding the strategy for inherent defects can be found in Leverant et al. 2000 and Wu et al. 2002.

\section{Strategy for Surface Damage-Based Defects}

In contrast with inherent defects that may be present anywhere in a component, surface damage-based defects are assumed to be concentrated in specific regions (e.g., bolt holes, surfaces subjected to abusive machining). A feature-based approach is used in which component risk is approximately equal to the sum of the risks of the individual features. Similar to a zone, each feature can have a number of unique characteristics associated with it. For a typical gas turbine engine disk, the number of features associated with a surface damage assessment is relatively small compared to the number of zones associated with an inherent defect-based assessment. Stress and temperature data, typically defined only at key features, can be defined directly by the analyst (i.e., no finite element results are required, Enright et al. 2003).

A new method has recently been developed for modeling surface damage-related crack growth using results from 3D finite element analysis (McClung et al. 2004, Waldhart et al. 2004). It is based on the assumption that a Mode I crack propagates in the plane normal to the maximum principal stress (for the dominant stress pair in a given mission profile) in a region that is idealized as a rectangular plate. The method can be summarized as follows:

- Specify an initial crack location at a node on the surface of a 3D finite element model

- Extract the six stress components at the initial crack location, and compute the magnitude and orientation of the maximum principal stress (MPS)

- Identify the orientation of a "slice plane" - a plane normal to the orientation of the MPS at the crack location

- Identify the location of points of intersection between the slice plane and the 3D finite elements, and compute stresses at the intersection points

- Create a new 2D finite element mesh on the crack plane consisting of triangular elements based on the intersection points using a Delaunay triangularization algorithm

- Define a rectangular region within the new 2D mesh that includes the initial crack location and orientation of a stress gradient vector

- Extract stresses along the stress gradient vector for use in 2D fracture mechanics computations

The method, recently implemented in DARWIN, is illustrated for an offset surface crack at a hole in a typical gas turbine engine component (Figure 3). As shown in Figure 3a, the analyst can import and manipulate a 3D finite element model directly in the GUI to specify the location of an initial crack. The GUI automatically computes the magnitude and orientation of the maximum principal stress and associated plane. Stresses on this plane are extracted to reveal a 2D cross section of 
the crack propagation plane (Figure $3 \mathrm{~b}$ ). The $2 \mathrm{D}$ cross section can then be used to specify the location and dimensions of a rectangular plate for fracture mechanics computations. This illustrates the applicability of the method to nonaxisymmetric geometries for probabilistic life prediction of general aerospace components. See Enright et al. 2003 for additional details regarding the probabilistic surface damage tolerance strategy.

\section{Computational Efficiency}

The target failure probability for gas turbine engine components subjected to inherent or surface damage-related defects is on the order of $10^{-9}$ on a per flight cycle basis (FAA 2001), or $10^{-5}$ on a cumulative basis. To achieve sufficient computational accuracy, a large number of Monte Carlo samples may be required. Since the computation time associated with predicting the crack propagation life associated with each Monte Carlo sample is nontrivial, a number of techniques have been developed/implemented in DARWIN over the past several years to improve computational efficiency. A summary of these techniques is indicated in Table 2 (see also Leverant et al. 2000).

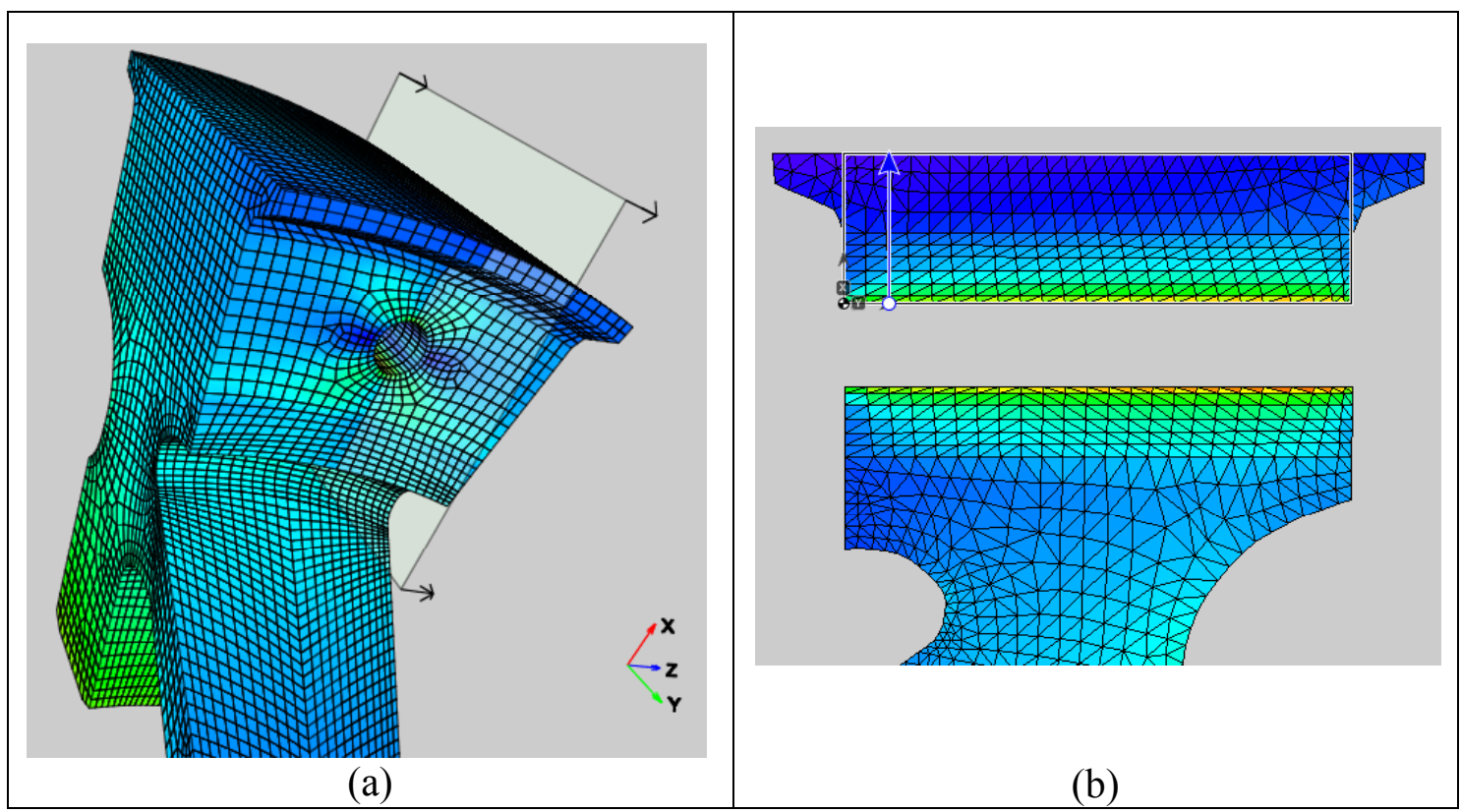

Figure 3. Illustration of a new method for definition of surface damage-related cracks using 3D finite element results: (a) import 3D finite element model, reorient to display and select initial surface crack location (GUI automatically identifies principal stress plane), and (b) slice model along principal stress plane to reveal crack propagation plane and associated rectangular plate for fracture mechanics assessment (McClung et al. 2004, Waldhart et al. 2004). 
Table 2. Techniques developed in DARWIN to address computational efficiency associated with probabilistic life prediction

\begin{tabular}{|c|c|c|c|}
\hline Technique & Classification & Description & Reference \\
\hline $\begin{array}{l}\text { Life } \\
\text { Approximation } \\
\text { Function }\end{array}$ & $\begin{array}{l}\text { Tailored response } \\
\text { surface }\end{array}$ & $\begin{array}{l}\text { Create tables of crack area } \\
\text { and cycles to failure for } \\
\text { use during Monte Carlo } \\
\text { simulation }\end{array}$ & $\begin{array}{l}\text { Wu et al. 2002, } \\
\text { Southwest } \\
\text { Research } \\
\text { Institute } 2003\end{array}$ \\
\hline $\begin{array}{l}\text { Importance } \\
\text { Sampling }\end{array}$ & $\begin{array}{l}\text { Zone-based } \\
\text { variance } \\
\text { reduction }\end{array}$ & $\begin{array}{l}\text { Combined technique of } \\
\text { numerical integration and } \\
\text { failure region-based } \\
\text { Monte Carlo simulation }\end{array}$ & $\begin{array}{l}\text { Wu et al. } 2002 \text {, } \\
\text { Huyse and } \\
\text { Enright } 2003\end{array}$ \\
\hline Zone Refinement & $\begin{array}{l}\text { Defect location } \\
\text { uncertainty }\end{array}$ & $\begin{array}{l}\text { Focused discretization of } \\
\text { zones based on relative } \\
\text { contribution to component } \\
\text { risk }\end{array}$ & $\begin{array}{l}\text { Millwater et al. } \\
2002\end{array}$ \\
\hline $\begin{array}{l}\text { Optimal } \\
\text { Sampling }\end{array}$ & $\begin{array}{l}\text { Component- } \\
\text { based variance } \\
\text { reduction }\end{array}$ & $\begin{array}{l}\text { Allocate Monte Carlo } \\
\text { samples to each zone } \\
\text { based on its relative } \\
\text { contribution to component } \\
\text { risk }\end{array}$ & $\begin{array}{l}\text { Enright and } \\
\text { Millwater 2002, } \\
\text { Enright et al. } \\
2004\end{array}$ \\
\hline $\begin{array}{l}\text { Distributed } \\
\text { Processing }\end{array}$ & $\begin{array}{l}\text { Parallel } \\
\text { processing }\end{array}$ & $\begin{array}{l}\text { Provide computational } \\
\text { framework for distributing } \\
\text { computational tasks to } \\
\text { multiple computers }\end{array}$ & $\begin{array}{l}\text { Millwater and } \\
\text { Guduru } 2004\end{array}$ \\
\hline
\end{tabular}

\section{Summary}

A probabilistic methodology has been developed to quantify the risk of fracture associated with rare metallurgical/manufacturing defects in aircraft gas turbine engine components. This paper summarizes the methodology, and provides a brief overview of the specific strategies developed for inherent and surface damage-related defects. A new method for defining surface damage-related crack growth using 3D finite element results is illustrated that is applicable to the probabilistic life prediction of general aerospace components.

\section{Acknowledgments}

This work was supported by the Federal Aviation Administration under Cooperative Agreement 95-G-041 and Grant 99-G-016. The authors wish to thank Joe Wilson (FAA Technical Center project manager) and Tim Mouzakis (FAA Engine and Propeller Directorate) for their continued support. The ongoing contributions of the Industry Steering Committee (Darryl Lehmann, Pratt \& Whitney; Jon Tschopp, General Electric; Ahsan Jameel, Honeywell; Jon Dubke, Rolls-Royce) are also gratefully acknowledged. 


\section{References:}

Aerospace Industries Association Rotor Integrity Subcommittee (1997). "The development of anomaly distributions for aircraft engine titanium disk alloys," Proceedings, 38th Structures, Structural Dynamics, and Materials Conference, Kissimmee, FL, April 7-10, 1997, 2543-2553.

Enright, M.P. and Millwater, H.R. (2002). "Optimal sampling techniques for zonebased probabilistic fatigue life prediction," Proceedings of the 43rd AIAA/ASME/ASCE/AHS/ASC Structures, Structural Dynamics, and Materials Conference, Non-Deterministic Approaches Forum, Denver, CO, April 22-25, AIAA Paper 2002-1383.

Enright, M.P., Huyse, L., and Millwater, H.R. (2004). "Adaptive optimal sampling methodology for zone-based probabilistic life prediction," Proceedings, 45th Structures, Structural Dynamics, and Materials Conference, Palm Springs, CA, April 19-22, 2004 (submitted).

Enright, M.P., Lee, Y-D, McClung, R.C., Huyse, L., Leverant, G.R., Millwater, H.R., and Fitch, S.K. (2003). "Probabilistic surface damage tolerance assessment of aircraft turbine rotors," Proceedings of the 48th ASME International Gas Turbine $\&$ Aeroengine Technical Congress, Atlanta, GA, June 16-19.

Federal Aviation Administration (2001). "Advisory Circular - Damage Tolerance for High Energy Turbine Engine Rotors", U.S. Department of Transportation, AC 33.14-1, Washington, DC.

Huyse, L., and Enright, M.P (2003). "Efficient statistical analysis of failure risk in engine rotor disks using importance sampling techniques," Proceedings of the 44th AIAA/ ASME/ ASCE/ AHS/ ASC Structures, Structural Dynamics, and Materials Conference, Non-Deterministic Approaches Forum, Norfolk, VA, April 7-10, AIAA Paper 2003-1838.

Leverant, G.R. et al. (2000). "Turbine Rotor Material Design - Final Report," Federal Aviation Administration, DOT/ FAA/ AR-00/64, Washington, DC.

Leverant, G.R., Littlefield, D.L., McClung, R.C., Millwater, H.R., Wu, Y-T. (1997). "A probabilistic approach to aircraft turbine material design," Proceedings of the 42nd ASME International Gas Turbine \& Aeroengine Technical Congress, Paper 97-GT-22.

Leverant, G.R., McClung, R.C., Millwater, H.R., and Enright, M.P (2003). "A new tool for design and certification of aircraft turbine rotors", Journal of Engineering for Gas Turbines and Power, ASME (accepted).

McClung, R.C., Enright, M.P., Lee, Y-D., Huyse, L., and Fitch, S.H.K (2004). "Efficient fracture design for complex turbine engine components," Proceedings of the 49th ASME International Gas Turbine \& Aeroengine Technical Congress, Vienna, Austria, June 14-17 (submitted).

Millwater, H.R. and Guduru, S. (2004). "Application of parallel processing methods to probabilistic fracture mechanics analysis of gas turbine disks," Proceedings, 45th Structures, Structural Dynamics, and Materials Conference, Palm Springs, CA, April 19-22, 2004 (submitted). 
Millwater, H.R., Enright, M.P., and Fitch, S.K. (2002). "A convergent probabilistic techniques for risk assessment of gas turbine disks subject to metallurgical defects," Proceedings of the 43rd AIAA/ASME/ASCE/AHS/ASC Structures, Structural Dynamics, and Materials Conference, Non-Deterministic Approaches Forum, Denver, CO, April 22-25, AIAA Paper 2002-1382.

Millwater, H., Fitch, S., Wu, Y-T., Riha, D, Enright, M., Leverant, G., McClung, C., Kuhlman, C., Chell, G., Lee, Y. (2000). "A probabilistically-based damage tolerance analysis computer program for hard alpha anomalies in titanium rotors," Proceedings of the 45th ASME International Gas Turbine \& Aeroengine Technical Congress, Munich, Germany, Paper No. 2000-GT-0421.

National Transportation Safety Board (1990). "Aircraft Accident Report - United Airlines Flight 232 McDonnell Douglas DC-10-10 Sioux Gateway Airport, Sioux City, Iowa, July 19, 1989," National Transportation Safety Board, NTSB/AAR90/06, Washington, DC.

Southwest Research Institute (2003). "DARWIN ${ }^{\circledR}$ User's Guide”. Southwest Research Institute, San Antonio, TX.

Waldhart, C., Enright, M.P., and Fitch, S.K. (2004). "Methodology for application of 3-D stresses to surface damage-based risk assessment," Proceedings, 45th Structures, Structural Dynamics, and Materials Conference, Palm Springs, CA, April 19-22, 2004 (submitted).

Wu, Y.T., Enright, M.P., and Millwater, H.R. (2002). "Probabilistic methods for design assessment of reliability with inspection," AIAA Journal , AIAA, 40 (5), 937-946. 